\title{
NERIS: European platform on preparedness for nuclear and radiological emergency response and recovery - Activities and perspectives
}

\author{
T. Schneider ${ }^{1,2}$, S. Lafage ${ }^{2}$, J. Bardelay ${ }^{3}$, T. Duranova ${ }^{4}$, E. Gallego ${ }^{5}$, F. Gering ${ }^{6}$, F. Hardeman ${ }^{7}$, \\ G. Hériard-Dubreuil ${ }^{8}$, C. Murith ${ }^{9}$, D. Oughton ${ }^{10}$ and W. Raskob ${ }^{11}$ \\ Chair of NERIS Platform. \\ 2 Nuclear Evaluation Protection Centre (CEPN), 28 rue de la Redoute, 92260 Fontenay-aux-Roses, France. \\ 3 Institute for Radiological Protection and Nuclear Safety (IRSN), BP17, 92263 Fontenay-aux-Roses Cedex, France. \\ 4 Nuclear Power Plants Research Institute (VUJE), Okružná 5, 91864 Trnava, Slovakia. \\ 5 Universidad Polytécnica de Madrid (UPM), José Gutiérrez Abascal, 2, 28006 Madrid, Spain. \\ ${ }^{6}$ Federal Office for Radiation Protection (BfS), Ingolstädter Landstr. 1, 85764 Oberschleißheim, Germany. \\ 7 Belgian Nuclear Research Centre (SCK-CEN), Boeretang 200, 2400 Mol, Belgium. \\ 8 MUTADIS, 5 rue d'Alsace, 75010 Paris, France. \\ 9 Federal Office of Public Health (FOPH), Schwarzenburgstrasse 165, 3097 Liebefeld, Switzerland. \\ 10 Norwegian University of Life Sciences (NMBU), ullevålsveien 72, 0454 Oslo, Norway. \\ 11 Karlsruhe Institute of Technology (KIT), Postfach 3640, 76021 Karlsruhe, Germany.
}

\begin{abstract}
Created in 2010, the aim of the NERIS platform is to establish a forum for dialogue and methodological development among all organisations and associations taking part in decision-making of protective actions in nuclear and radiological emergencies and recovery in Europe. The objectives of the platform are to contribute to improving the effectiveness of current approaches for preparedness, promoting more coherent approaches, identifying gaps and need for further developments, addressing new and emerging challenges, and maintaining and improving know-how and technical expertise in this field. This paper describes the missions, the organisation and the activities of the platform as well as the key components of its strategic research agenda.
\end{abstract}

Keywords: NERIS platform / emergency and recovery preparedness / research needs

\section{Introduction}

Since the Chernobyl accident, research programmes have been set up to further investigate and improve nuclear emergency and recovery preparedness and management. These programmes notably include advances in decision support tools, and improved methods for information and data exchange as well as participatory governance through the setting up of local-national cooperation processes. To foster the cooperation in this field, several European organisations involved in these programmes established the NERIS Platform in June $2010^{1}$. The Fukushima accident has largely reinforced the necessity to further develop the common thinking in this field and to establish cooperation between European and foreign organisations. With the support of the European Commission from Febru-

\footnotetext{
1 NERIS Web site: www.eu-neris.net
}

ary 2011 to January 2014 (through the NERIS TP project ${ }^{2}$ ), the NERIS platform was set up to organise this cooperation (Raskob et al., 2014).

The vision of the NERIS platform is that "by 2020, all European organisations that are members of the association are sharing common views and common approaches and are developing and using compatible technology and methods for consequence management of emergencies". In respect to this vision, cooperation with international organisations has been established with a mandate to harmonise their response in Europe and worldwide and to encourage them to become aware of NERIS's scientific capabilities and research develop-

2 Towards a self-sustaining European Technology Platform (NERIS-TP) on Preparedness for Nuclear and Radiological Emergency Response and Recovery - Euratom for Nuclear Research and Training Activities: Fission 2010: 269718. 
ments. Dialogues have already been established, notably with the European Commission, Heads of the European Radiological Protection Competent Authorities (HERCA), International Commission on Radiological Protection (ICRP), International Atomic Energy Agency (IAEA), Committee for Radiation Protection and Public Health (CRPPH) of the OECD/NEA, World Health Organisation (WHO), Group of Municipalities with Nuclear Facilities (GMF), and Nuclear Transparency Watch (NTW).

NERIS prepared its strategic research agenda by also taking into account the need for further research identified after the Fukushima accident. This paper presents the organisation and objectives of the NERIS platform, the key components of the strategic research agenda and the cooperation established with different European and international organisations.

\section{Organisation and objectives}

Created in June 2010 as a network of European organisations involved in emergency and recovery preparedness and management, the NERIS platform was registered on the 28th of August 2012 as a legal European Association under French law, to reinforce its structure and ensure its sustainability. Currently, 59 organisations from 24 different countries are members of the NERIS platform, with 28 organisations (called "NERIS supporting organisations") being legal members of the NERIS association and supporting it financially.

A Management Board of 10 elected members from the NERIS supporting organisations operates the platform. This board defines the work programme and follows up its implementation. A technical and scientific secretariat is in charge of the administration of the platform and provides practical assistance for the organisation of its various activities. The NERIS research and development $(\mathrm{R} \& \mathrm{D})$ Committee is composed of 12 members and elaborates the strategic orientation of the platform based on the new areas of interest identified by the Working Groups and the expectations and demands of the NERIS partners.

The objectives of the platform are to contribute to improving the effectiveness of current approaches for preparedness, promoting more coherent approaches, identifying gaps and need for further developments, addressing new and emerging challenges, and maintaining and improving know-how and technical expertise in this field.

To achieve its objectives, three working groups have been created so far:

- a working group on "the practical implementation of the ICRP recommendations" to develop guidance and adapt existing Decision Support Systems to the new approach for emergency and recovery preparedness and management;

- a working group on "processes and tools for emergency and rehabilitation preparedness at a community level" to develop user-friendly processes and tools to assist communities in preparing for local cooperation;

- a working group on "management of contaminated goods" to contribute to the development of strategies, guidance and tools for the management of contaminated products.
Currently, two EC research projects are strongly linked to the NERIS platform organisations and activities; the NERIS-TP Project (2011-2014) and the PREPARE Project (2013-2016). NERIS also supports the organisation of training courses as well as the RODOS users' group.

\section{Key topics of the NERIS strategic research agenda}

The Strategic Research Agenda (SRA) has been structured in three main research areas, covering new challenges in atmospheric \& aquatic modelling, new challenges for better dose assessments and decision support based on improved knowledge, and new challenges in stakeholder involvement and local preparedness and communication strategies (NERIS, 2014).

\subsection{Area 1: New challenges in atmospheric \& aquatic modelling - Need for improvement}

Area 1 deals with dispersion of radioactive materials (in solid or gaseous form) in the atmosphere or in water systems. Most of the challenges in atmospheric dispersion are related, on the one hand, to dispersion in urban and confined environments, and on the other hand to very short- or very longduration releases (explosions and Fukushima-type releases). Today, new programming techniques and more efficient algorithms enable modelling of different urban environments and very short-duration releases. Development of rapid data assimilation techniques and inverse modelling are associated with all kinds of dispersion modelling and should be further improved to obtain better situation awareness in the very early phase of an emergency. The same applies to source term estimation.

The Fukushima accident proved the importance of dispersion of radionuclides in coastal environments, and pointed out a real need to develop site-specific models. Furthermore, any coastal dispersion model should be linked with an ocean model for driving forces. Contamination of drinking water with radionuclides in intentional or accidental releases is also an area that requires further research. In general, the linkage between transport and dispersion modelling and dose assessment models has to be intensified and interfaces harmonised.

\subsection{Area 2: New challenges for better dose assessments and decision support based on improved knowledge: source term, scenarios, etc.}

Area 2 deals with Decision Support Systems (DSS) and the decision-making processes in case of nuclear or radiological emergencies, including the longer-term rehabilitation issues. On one hand, the DSS include several simulation models such as dispersion and dose assessment models, and in this respect, they are closely related to topics in Area 1 . Source term estimations are of primary importance, particularly the knowledge of the radionuclide composition, to develop appropriate countermeasure strategies. In this respect, estimation of the source term based on in-plant data and the development of optimised 
monitoring strategies are of high priority. Developing computational models to simulate the recommendations for the countermeasures on the operational/tactical level can better link the crisis centre to the local commander-in-chief (Command and Control (C2) systems).

The Fukushima accident demonstrated the need for a European platform where data and information of governmental and non-governmental organisations can be collected and made available to all interested parties. This kind of access/exchange platform might be an important tool in order to achieve more coherent decisions. In addition, the experience from the Fukushima accident highlighted the importance of understanding and possibly improving/fostering the decisionmaking processes at the local, regional and national levels. Various issues have been identified to structure the decisionmaking processes better and provide further guidance for their implementation. This comprises providing accurate information, favouring efficient use of existing DSS and tools, and allowing a better allocation of resources for achieving efficient protective strategies responding to the expectations of the various stakeholders in emergency and recovery phases.

\subsection{Area 3: New challenges in stakeholder involvement, local preparedness and communication strategies}

Area 3 deals with stakeholder involvement, local preparedness and communication strategies in an emergency and recovery situation. In this area, communication and information issues are of great importance due to a huge demand for information and measurement results, use of modern social media through the internet, and possible contradictory information being available. The Fukushima accident demonstrated that new European stakeholders were engaged in decisionmaking to protect European citizens in Japan. Foreign governments meanwhile advised differently on protective actions to their citizens, which created confusion among the European and Japanese public. Iodine tablets were sold out in some European countries without proper justification, some countries introduced restrictions on food import, many embassies relocated from Tokyo, etc. On the other hand, the follow-up of the management of the consequences of the Fukushima accident in Japan leads to revisit the existing framework for public participation, notably in the perspective of the Aarhus Convention $^{3}$, and ways for improving the implementation of protection strategies. In this context, the objective in this area is to further improve the strategies for ensuring appropriate stakeholder engagement, information exchange and dialogue between different actors (stakeholders, public, authorities) in emergency and recovery preparedness and response.

\footnotetext{
3 Aarhus Convention: The United Nations Economic Commission for Europe's Convention on Access to Information, Public Participation in Decision-making and Access to Justice in Environmental Matters. http://en.wikipedia.org/wiki/Aarhus_Convention
}

\section{European and international cooperation}

The NERIS platform is now facing new challenges for its development. In addition to the continuous cooperation with organisations involved in the management of the consequences of the Chernobyl accident (mainly from Ukraine and Belarus), the experience of the Japanese organisations involved in the emergency and recovery response of the Fukushima accident is of primary importance for the NERIS community. Thus, cooperation has been established with several organisations in Japan to share their experience, notably:

- Fukushima University;

- Fukushima Medical University;

- the Central Research Institute of Electric Power Industry (CRIEPI), and

- the Institute for Global Environmental Strategies (IGES) (coordinator of the FAIRDO ${ }^{4}$ project).

This cooperation is progressively growing with the participation of Japanese researchers and stakeholders in different NERIS workshops (or linked to EC research projects) as well as participation of NERIS researchers in meetings organised by Japanese colleagues. It is a crucial task for the NERIS platform to facilitate the sharing of experience drawn (and to be drawn in the future) from the Fukushima accident.

On 5 December 2013, a Memorandum of Understanding (MoU) was signed between the four established platforms in radiation protection in Europe to confirm their joint commitment towards the consolidation and implementation of a strategic vision of radiation protection research in Europe:

- MELODI (low-dose risk research platform);

- ALLIANCE (radioecology platform);

- EURADOS (radiation dosimetry platform), and

- NERIS (emergency response and recovery platform).

For this purpose, it was decided to establish a Joint Radiation Protection Research Roadmap Committee, to coordinate the SRAs and priority roadmaps of the four platforms, and set up joint research calls in the framework of the European OPERRA research project (Open Project for the European Radiation Research Area). The second step is the participation of the NERIS platform, together with the other signatories of the $\mathrm{MoU}$, in the elaboration of the European Joint Programming CONCERT project on the organisation of the research in radiation protection in Europe in the perspective of Horizon 2020 of the European Commission.

\section{Perspectives}

The sustainability of the NERIS platform is now a reality. With the end of the NERIS-TP project, the platform is now relying on the NERIS Supporting Organisations. In addition, the results of the NERIS-TP research project and the developments within the PREPARE research project demonstrate

\footnotetext{
${ }^{4}$ FAIRDO: Fukushima Action Research on Effective Decontamination Operation.
} 
the usefulness of the NERIS platform to promote the research on emergency response and recovery issues involving a large number of European organisations. This role needs to be reinforced and the results should now be shared and discussed with a broader community.

For the future, one of the key challenges is the development of a common roadmap on radiation research in Europe with the other research platforms (MELODI, ALLIANCE and EURADOS) in the perspective of Horizon 2020. This roadmap will have to be elaborated taking into account the first lessons drawn from the management of the consequences of the Fukushima accident, as well as the evolution of international and national organisations' emergency and recovery strategies. In this perspective, the work performed in the
NERIS Platform will necessarily be explored in more depth and shared with all interested stakeholders.

\section{References}

NERIS (2014) Strategic Research Agenda of the NERIS Platform. Version 2 (Draft04), April 8, 2014 - http:// www.eu-neris.net/index.php/library/general/document/ strategic-research-agenda-of-the-neris-platform-v2.html

Raskob W., Croteau C., Schneider T., Mustonen R., Duranova T., Liland A., Andronopoulos S., Hoe S. (2014) NERIS-TP final report. NERIS-TP(WP6)-(14)-03, March 2014.

Cite this article as: T. Schneider, S. Lafage, J. Bardelay, T. Duranova, E. Gallego, F. Gering, F. Hardeman, G. Hériard-Dubreuil, C. Murith, D. Oughton, W. Raskob. NERIS: European platform on preparedness for nuclear and radiological emergency response and recovery - Activities and perspectives. Radioprotection 51(HS1), S5-S8 (2016). 